\title{
Public Security Road Traffic Management Strategy Based on Big Data Application
}

\author{
Mu Xiaoyang \\ Department of Image and Network Investigation, Railway Police College, Zhengzhou, Henan, 450053, \\ China \\ email: muxiaoyang@rpc.edu.cn
}

Keywords: Big Data, Public Security Road Traffic Management, Problems, Measures

\begin{abstract}
With the continuous development of science and technology, information, intelligence has become the current mainstream, big data as a unique symbol of the information age, more and more attention, widely used in various industries, public security road traffic system is no exception. In recent years, the development of intelligent transportation is very rapid. Big data is the basis of solving intelligent transportation scheme, and its importance is self-evident.
\end{abstract}

\section{Introduction}

The continuous advancement of information has gradually changed the people's daily life, including work, life, thinking and problem-solving, and so on, it is no exaggeration to say that at present we have entered the information age, which is commonly referred to as the big data era. Big data in commercial applications have achieved very bright results, favored by many industries. With the continuous development of our country's economy, the road traffic mileage has been increasing, the number of motor vehicles has increased year by year, road safety has become a matter of great concern, the traditional traffic management mode has been unable to meet the current development needs of traffic management. Public security organs began to use big data technology to strengthen police construction, and achieved gratifying results. Public security road traffic management as a part of the whole public security police management should also actively explore the use of big data technology to improve the public security road traffic management information level to meet the needs of public security road traffic management in the new era.

\section{The Concept of Big Data}

Big data refers to the use of advanced technology to collect and process the massive data generated in social life, and its main function is to analyze and calculate the data, not to simply store it. It has four obvious characteristics, that is, the amount of data is huge, the form is diversified, the value density is low, the processing speed is fast, its amount of data can be as high as EB level, to process these diversified data in a very short time, and to find valuable information from it, this is the meaning of big data.

\section{Public Security Road Traffic Management Concept}

Public security road traffic management refers to the general term for carrying out effective management activities of various road traffic events according to relevant laws and regulations in order to achieve higher economic and social benefits. In real life, there are many objective and subjective factors that affect the road traffic management, which are related to the local economic conditions, natural and geographical conditions, the mode of transportation, the relevant regulations of the state and local government, the state of infrastructure and the quality of the people. 


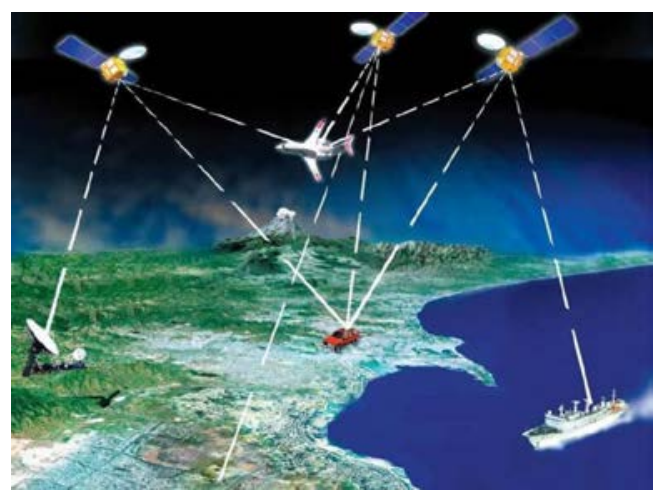

Figure 1 Information traffic

\section{Application of Big Data in Public Security Road Traffic Management}

Because the public security road traffic management work involves a wide range of people, many participants, traffic behavior and traffic management mode together produce huge volume of data, which makes the public security road traffic management situation very severe, but the contradiction between people's traffic service demand and supply is seriously unbalanced, and the traffic guarantee task is heavy and the police force is insufficient is more and more prominent at present. In general, big data in public security road traffic management by the following several aspects of the role.

\subsection{Provides Data Base Support for Public Security Traffic Management}

The wide application of big data can promote the role of information, people through modern science and technology to improve the utilization of resources, improve the traditional road traffic management mode, scientific and rational allocation of all kinds of resources, improve work efficiency. The mass data generated by urban traffic can enrich and expand the database of traffic management departments continuously. Similarly, the accumulated data can provide valuable data resources for public security traffic management, rely on advanced data processing technology to analyze and process the collected mass data, make correct decision, and then effectively manage the urban traffic behavior to form an intelligent closed-loop system. It mainly includes dynamic and static traffic information collection, vehicle driving service basic data management, traffic management law enforcement summary data management and road traffic association data management.[1].

\subsection{Widening Public Security Traffic Management Thinking}

The focus of big data is to predict what will happen in the future, and to maximize the ability of human pre-judgment. With the wide application of big data in police management in our country, the public security road traffic management layer also deeply realizes the importance of big data, it is not only a simple data storage, but also an advanced information technology with predictive function, which can change human understanding, broaden the channels of communication with the world, and make good use of big data can promote the high quality development of public security road traffic management.

\subsection{Promoting the Intelligentization of Public Security Road Traffic Management}

The traditional public security road traffic management relies on the strength of the police and the key points, but under the condition of the continuous expansion of road construction and the continuous growth of the number of motor vehicles, the traditional public security road traffic management mode has been far from keeping up with the needs of the development of the new era, which requires the public security road traffic management department to change the management concept and management thinking, optimize the management means and management methods, improve the management ability and management level, realize the ultimate goal of information, scientific and modernization of public transportation management, and make a greater contribution 
to the people's travel. Big data can give full play to the advantages of information integration and realize the scientific allocation and reasonable prediction of transportation resources [2].

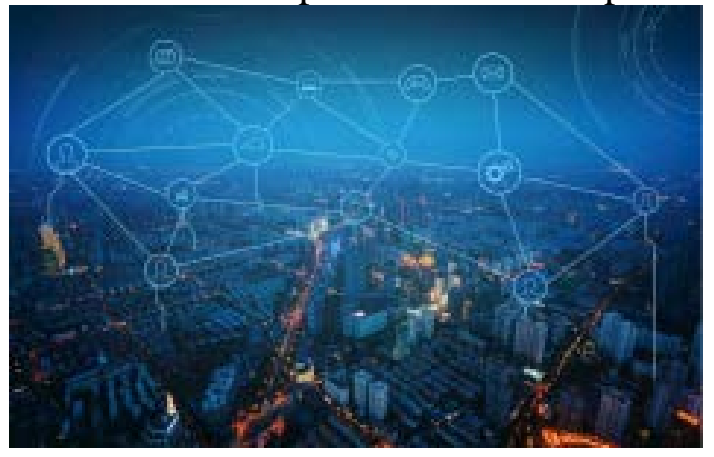

Figure 2 Smart City

\subsection{Improved Efficiency of Traffic Management}

The application of big data in traffic control system can effectively improve the efficiency. The first is the rational deployment of police force through flow monitoring. Using big data technology to analyze the traffic data of various toll stations, bayonets and checkpoints, the dynamic situation of local traffic flow is accurately counted, which provides a scientific basis for the rational setting of the bayonet, and at the same time provides data support for the accurate regulation by using its powerful statistical ability to the operation of trucks, dangerous goods vehicles and passenger cars in the district. The second is to strengthen the vehicle identification ability to facilitate process control. Big data can make law enforcement officers better understand the high incidence of illegal vehicles, illegal vehicle properties and so on, so as to be targeted in daily publicity and education. The third is to improve work efficiency through data analysis. Through the big data can analyze the occurrence of the main illegal behavior, get the information of the high incidence of accidents, the high incidence period, the concentrated performance of illegal behavior, the commonness of illegal drivers and so on, and make corresponding measures according to the information to effectively improve the work of the police

\section{Problems of Public Security Road Traffic Management in the Big Data Era}

Big data technology has a strong predictive ability, but there are some problems.

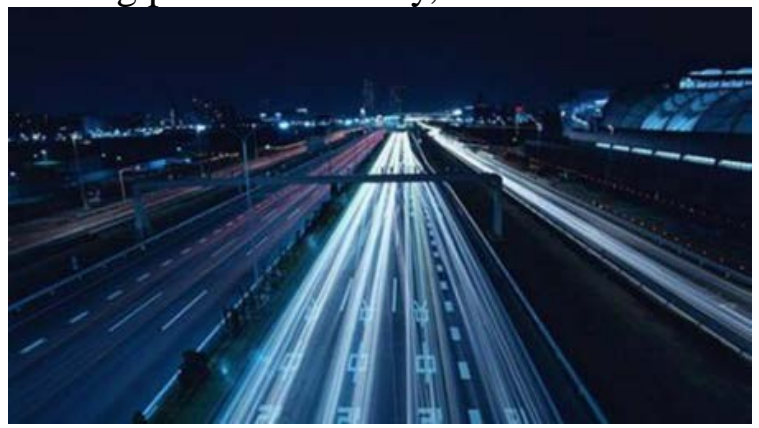

Figure 3 Big data traffic management

\subsection{Insufficient Standardization of Data Acquisition}

Big data is a new concept, many grass-roots units have insufficient understanding of the importance of data, often think that big data is the scope of the national science and technology department, and the unit has not too much to do a good job of big data construction enthusiasm is not high, it is difficult to form an overall force. But in fact, the application of big data needs massive data as support, through the analysis of a large number of facts to study its occurrence law, so as to achieve the effect of prevention, if the data provided by grass-roots units are not comprehensive, timely, inaccurate and so on, it will affect the accuracy of the analysis of big data technology and the scientific nature of taking countermeasures. 


\subsection{High Cost of Big Data Applications}

The cost of big data in data acquisition, storage and processing is relatively high, because the collection of massive data mainly depends on a large number of traffic detectors, and the diversity of big data itself requires the diversity of traffic detectors that provide data. The purchase, operation and maintenance of these traffic detectors are very expensive.

\subsection{Inadequate System}

At present, the public security road traffic management departments and the law enforcement police lack innovative consciousness in the use of new technology, especially in the application of data, most of them are only stuck in the analysis of traffic accidents themselves, so it is difficult to apply the data to the overall accident analysis and pre-judgment.

\section{Measures to Optimize Public Security Road Traffic Management in Big Data}

\subsection{Integration of Transport Data Resources}

At present, the data information is extremely complicated, the traffic information big data is no longer confined to people, roads and vehicles, and the data information between other relevant departments is equally important. First, it is necessary to strengthen communication and communication with traffic management and transportation management departments, so that drivers, car owners, vehicle conditions, vehicle running time and route, should carry real load and other information sharing. The second is to strengthen communication and exchange with urban construction departments to achieve the area of road mileage, road conditions, natural geographical environment and other information sharing. Third, strengthen the communication and exchange with the operating places, so as to share the parking information of each business place. The fourth is to strengthen communication with social software application developers, stimulate the enthusiasm of the masses to participate in data collection, broaden the channels of data collection, and build a perfect big data platform for public security road traffic system [3].

\subsection{Increase Investment in Smart Devices}

Increase investment in smart devices. One is to replace the traditional traffic signal light with the intelligent traffic signal light. According to the traffic flow of different junctions and sections in the rush hour, scientific and rational distribution of traffic time, constantly improve the traffic efficiency and road use efficiency at intersections. The second is to replace the traditional traffic sign with the intelligent traffic sign. Based on the natural meteorological data, it is shown on the intelligent traffic sign after analysis and processing to guide the driver to make the corresponding countermeasures. The third is to upgrade the traditional parking system, dynamically feedback the number of parking spaces available in the current parking lot through the intelligent parking system, and reduce the behavior of drivers blindly searching for parking spaces or even parking in violation of regulations, so as to maximize the utilization of public resources.

\subsection{Standard Interconnection Platform}

Adopting the method of "combining static and static" to speed up the construction of public security road traffic information platform under the background of big data, to make dynamic management have speed, static management has depth, and to provide people with real convenience for traffic travel.

Big data brings a lot of convenience to our life and work, and provides a good foundation for the continuous development of public security road traffic management, but we must correctly grasp the key to let big data truly serve the people.

\section{Conclusion}

The continuous advancement of information has gradually changed the people's daily life, 
including work, life, thinking and problem-solving, and so on, it is no exaggeration to say that at present we have entered the information age, which is commonly referred to as the big data era. Big data in commercial applications have achieved very bright results, favored by many industries. With the continuous development of our country's economy, the road traffic mileage has been increasing, the number of motor vehicles has increased year by year, road safety has become a matter of great concern, the traditional traffic management mode has been unable to meet the current development needs of traffic management. Public security organs began to use big data technology to strengthen police construction, and achieved gratifying results. Public security road traffic management as a part of the whole public security police management should also actively explore the use of big data technology to improve the public security road traffic management information level to meet the needs of public security road traffic management in the new era.

\section{Acknowledgements}

1) 2019 Henan higher education teaching reform research and practice project "research and practice of core elements of intelligent traffic police professional construction based on discipline integration" (2019sjglx472);

2) The 2019 teaching reform research project of Railway Police College "Research on key issues of training traffic management engineering professionals in the era of intelligent transportation" (jy2019z03).

\section{References}

[1] Shao Li, Zheng Weijin. Public security road traffic management strategy based on big data application. Journal of Shanghai College of Public Security, vol. 26, no. 01, pp. 46-53, 2016.

[2] Li Biao, Dong Kaifan, Feng Chun Fang. A study on the Intelligent Architecture of New Generation Public Security Traffic Management. China Public Safety (academic Edition), no. 03, pp. 72-76, 2019.

[3] Liu Tao. Research on Traffic Management Strategy of Nanchang Traffic Control Bureau based on big data. Jiangxi University of Finance and Economics, 2017. 